\title{
Searching for tics
}

\author{
Philip W. Tipton \\ Department of Neurology, Mayo Clinic Florida, Jacksonville, United States
}

\begin{abstract}
Introduction. In the current edition, Szejko and colleagues describe a subset of patients with Gilles de la Tourette syndrome (GTS) who had dystonic tics (DTs), which occurred more frequently in those with a greater number of tics and likely contribute to impairment.

Clinical reflections. DTs manifest as an abnormal posture that may be difficult to distinguish from other movements, such as dystonia and other tic types. Electromyography is an invaluable tool that can aid clinicians in making this important distinction.

Clinical implications. Accurately diagnosing these movements can significantly impact treatment decisions and contribute to more homogenous research populations.
\end{abstract}

(Neurol Neurochir Pol 2019; 53 (5): 315-316)

Gilles de la Tourette syndrome (GTS) is diagnosed in individuals who have two or more motor tics and at least one phonic tic for at least one year's duration beginning before age 18 [1]. Patients with GTS often have comorbid psychiatric problems that, coupled with tics, can lead to substantial impairment. Research has sought to characterize the phenotypic variability among those with GTS in order to better understand disease mechanisms and identify elements that have the greatest impact on quality of life. Accomplishing these goals will allow clinicians to more effectively tailor treatment to an individual's specific needs. Szejko et al. have nicely contributed to this effort and found that $73.9 \%$ of patients with GTS developed dystonic tics (DTs) [2]. They also provided a thorough characterization of their cohort of 153 patients with DTs. Their attention to detail highlights the importance of accurately differentiating tics from other movement phenomena, taking an account of one's complete tic repertoire, and correctly identifying types of tics, all of which can have a significant impact on treatment.

Tics are stereotypical movements sometimes described as semivoluntary or unvoluntary to highlight that they are not truly involuntary [3] unlike some other movement phenomena, such as dystonia, which is an involuntary sustained or intermittent co-contraction of muscle agonist and antagonists resulting in abnormal movements and/or postures [4]. Simple tics often have a jerk-like appearance and may be differentiated from other jerking movements by their serotyped nature and other attributes, including a premonitory urge that resolves when the tic is completed. Szejko et al. provide a nice table summarizing characteristics to aid in differentiating tics from dystonia [2]; however, there are limitations to an approach based solely on clinical history and observation as illustrated by the fact that $90 \%$ of adults and only $37 \%$ of children endorse a hallmark premonitory urge $[5,6]$. Moreover, simple motor tics may be misidentified as myoclonus thus leading the clinician to misdiagnosis. EMG is a useful technique that can aid in differentiation among these [7] and should be considered an integral extension of the neurological examination. Measuring burst duration enables one to categorize tics as clonic $(<100 \mathrm{~ms})$ or dystonic $(>300 \mathrm{~ms})[8]$. This is a distinction that may escape the sensitivity of clinical observation and only consistently accomplished with EMG.

Clinicians should be aware that individuals with GTS may have hyperkinetic movements in addition to tics, such as tardive chorea or tardive dystonia [9]. Accurately identifying these movements, which may mimic tics, can have a significant impact on treatment decisions, such as whether to increase or decrease the dosage of a dopamine antagonist like aripirazole, which is commonly used to treat tics [10]. The wrong decision could have serious and potentially irreversible consequences given the association between these medications and extrapyramidal side effects. Once an accurate and specific diagnosis of tics is established, appropriate treatments can be pursued. The American 
Academy of Neurology recently published new guidelines for the treatment of tic disorders [11]. Comprehensive Behavioral Intervention for Tics (CBIT) is the mainstay of the nonpharmacological treatment arm while pharmacological options include $a$-adrenergic agonists, antipsychotics, vesicular monoamine transporter-2 inhibitors, and botulinum toxin injections, the last of which has particular applicability to those with dystonic tics [12]. Botulinum toxin may also be used to treat laryngeal tics [13] and has even been shown to reduce the premonitory urge [14].

To effectively treat their patients, clinicians must compile a patient's tic inventory and determine their impact on one's life. This can be accomplished with various rating scales, such as the Yale Global Tic Severity Scale (YGTSS) [15, 16]. Szejko and colleagues made several interesting observations including the average age of onset of DTs 3.7 years after development of their first tic suggesting that most individuals do not present with DTs [2]. They also showed that the presence of DTs was more common in those with more tics overall. Previous reports have shown co-occurance of tics and dystonia [17] as well as cosegregation of eye-winking tics, frequent eye-blinking and blepharosm with a family $[18,19]$, raising the question of a shared mechanism. This idea has since been strengthened by identification of a shared mutation within the guanosine triphosphate cyclohydrolase I gene (GCHI) in a Danish family with dopa-responsive dystonia and GTS [20].

While the first step in evaluating movement disorders is accurately identifying the movement phenomenon, clinicians must be aware that not all phenomena are 'pure, i.e. tremor or tics, but can have characteristics of multiple movement phenomena simultaneously, e.g. DTs. Differentiating tics from dystonia as well as correctly identifying the type of tic is necessary for clinicians to provide appropriate treatment options, properly counsel their patients, and to better homogenize patient populations so that higher quality research studies may be conducted.

\section{Conflict of interests / Funding: None declared.}

\section{Abbreviations}

GTS - Gilles de la Tourette syndrome

DTs - Dystonic tics

Cts - Clonic tics

CBIT - Comprehensive Behavioral Intervention for Tics YGTSS - Yale Global Tic Severity Scale

\section{References}

1. American Psychiatric Association. Diagnostic and statistical manual of mental disorders, 5th ed (DSM-5). Washington, DC: American Psychiatric Association; 2013.

2. Szejko N, Jakubczyk A, Dunalska A, et al. Dystonic tics in patients with Gilles de la Tourette syndrome. Neurol Neurochir Pol. 2019; 53(5): 335-340, doi: 10.5603/PJNNS.a2019.0046.

3. Fahn S, Jankovic J, Hallett M. Psychogenic movement disorders. Prin-ciples and Practice of Movement Disorders [Chapter 16: Tics and Tou-rette syndrome]. 2011: 350-379, doi: 10.1016/ b978-1-4377-2369-4.00025-1.
4. Albanese A, Bhatia K, Bressman SB, et al. Phenomenology and classification of dystonia: a consensus update. Mov Disord. 2013; 28(7): 863-873, doi: 10.1002/mds.25475, indexed in Pubmed: 23649720.

5. Kwak C, Dat Vuong K, Jankovic J. Premonitory sensory phenomenon in Tourette's syndrome. Mov Disord. 2003; 18(12): 1530-1533, doi: 10.1002/mds.10618, indexed in Pubmed: 14673893.

6. Banaschewski T, Woerner W, Rothenberger A. Premonitory sensory phenomena and suppressibility of tics in Tourette syndrome: developmental aspects in children and adolescents. Dev Med Child Neurol. 2003; 45(10): 700-703, doi: 10.1017/s0012162203001294, indexed in Pubmed: 14515942.

7. Panyakaew $\mathrm{P}$, Cho HJ, Hallett M. Clinical Neurophysiological Evaluation for Simple Motor Tics. Clin Neurophysiol Pract. 2016; 1: 33-37, doi: 10.1016/j.cnp.2016.04.001, indexed in Pubmed: 27777987.

8. Jankovic J, Stone L. Dystonic tics in patients with Tourette's syndrome. Mov Disord. 1991; 6(3): 248-252, doi: 10.1002/mds.870060309, indexed in Pubmed: 1922130.

9. Kompoliti K, Goetz CG. Hyperkinetic movement disorders misdiagnosed as tics in Gilles de la Tourette syndrome. Mov Disord. 1998; 13(3): 477 480, doi: 10.1002/mds.870130317, indexed in Pubmed: 9613740.

10. Janik P, Szejko N. Aripiprazole in treatment of Gilles de la Tourette syndrome - New therapeutic option. Neurol Neurochir Pol. 2018; 52(1): 84 87, doi: 10.1016/j.pjnns.2017.10.015, indexed in Pubmed: 29154107.

11. Pringsheim T, Okun MS, Müller-Vahl K, et al. Practice guideline recommendations summary: Treatment of tics in people with Tourette syndrome and chronic tic disorders. Neurology. 2019; 92(19): 896-906, doi: 10.1212/WNL.0000000000007466, indexed in Pubmed: 31061208.

12. Jankovic J. Botulinum toxin in the treatment of dystonic tics. Mov Disord. 1994; 9(3): 347-349, doi: 10.1002/mds.870090315, indexed in Pubmed: 8041378.

13. Vincent DA. Botulinum toxin in the management of laryngeal tics. J Voice. 2008; 22(2): 251-256, doi: 10.1016/j.jvoice.2006.08.014, indexed in Pubmed: 17056228.

14. Kwak $\mathrm{CH}$, Hanna PA, Jankovic J. Botulinum toxin in the treatment of tics. Arch Neurol. 2000; 57(8): 1190-1193, doi: 10.1001/archneur.57.8.1190, indexed in Pubmed: 10927800.

15. Leckman JF, Riddle MA, Hardin MT, et al. The Yale Global Tic Severity Scale: initial testing of a clinician-rated scale of tic severity. J Am Acad Child Adolesc Psychiatry. 1989; 28(4): 566-573, doi: 10.1097/00004583198907000-00015, indexed in Pubmed: 2768151.

16. Martino D, Pringsheim TM, Cavanna AE, et al. Members of the MDS Committee on Rating Scales Development. Systematic review of severity scales and screening instruments for tics: Critique and recommendations. Mov Disord. 2017; 32(3): 467-473, doi: 10.1002/mds.26891, indexed in Pubmed: 28071825.

17. Stone LA, Jankovic J. The coexistence of tics and dystonia. Arch Neurol. 1991; 48(8): 862-865, doi: 10.1001/archneur.1991.00530200104028, indexed in Pubmed: 1898264.

18. Elston JS, Granje FC, Lees AJ. The relationship between eye-winking tics, frequent eye-blinking and blepharospasm. J Neurol Neurosurg Psychiatry. 1989; 52(4): 477-480, doi: 10.1136/jnnp.52.4.477, indexed in Pubmed: 2738590.

19. Németh AH, Mills KR, Elston JS, et al. Do the same genes predispose to Gilles de la Tourette syndrome and dystonia? Report of a new family and review of the literature. Mov Disord. 1999; 14(5): 826-831, indexed in Pubmed: 10495045.

20. Romstad A, Dupont E, Krag-Olsen B, et al. Dopa-responsive dystonia and Tourette syndrome in a large Danish family. Arch Neurol. 2003; 60(4): 618-622, doi: 10.1001/archneur.60.4.618, indexed in Pubmed: 12707079 . 